\title{
Penile amputation following adult circumcision
}

\author{
Uwakwe Cosmas Mba, Ifeanyi C. Ugwu \\ Department of Surgery, Engu State University Teaching Hospital, Parklane, Enugu, Nigeria
}

\begin{abstract}
Male circumcision is a routine cultural ritual in the neonates among Igbo tribe in southeast Nigeria. Adult circumcision is not a common practice and circumcision is rarely complicated by amputation. It is a major source of distress for the patient, and a reconstructive challenge to the care giver. Use of skin graft has been described in glans resurfacing. However, it is difficult to keep the graft in place in the early post operative period.

A 32 years-old man presented to us with penile amputation and urethral stenosis following circumcision by a midwife. Initial attempt at reconstruction failed before he was referred to us. We used Split Thickness Skin Graft (STSG) with tie-over dressing for resurfacing. Penile amputation is an uncommon complication of adult circumcision and should be left for professionals to avoid such mishap. Satisfactory outcome can be achieved by STSG if sufficient length is preserved.
\end{abstract}

\section{Introduction}

Male circumcision is routinely performed for cultural reasons among Igbo tribe in southeast Nigeria and is usually carried out in the neonatal period, precisely after two native weeks (day 8). Adult

Correspondence: Uwakwe Cosmas Mba, Department of Surgery, ESUT Hospital, Parklane, P.M.B.1030, Enugu.

Tel.: $08036003969-08121130446$

E-mail: ndiuwamba@gmail.com

Key words: Penile Amputation; Adult Circumcision; Split thickness skin graft.

Contributions: UCM conceived the idea and constructed the format for the article, adapted the patients case summary for the article, revised the manuscript, expanded literature review and rewrote the article, read and approved the final manuscript, and agreed to be accountable for all aspects of the work. ICU drafted the patients case summary, did initial literature search and drafted the manuscript, read and approved the final manuscript, and agreed to be accountable for all aspects of the work.

Received for publication: 26 June 2020.

Revision received: 21 July 2020.

Accepted for publication: 30 July 2020.

This work is licensed under a Creative Commons Attribution NonCommercial 4.0 License (CC BY-NC 4.0).

(C) Copyright: the Author(s),2020

Licensee PAGEPress, Italy

Annals of Clinical and Biomedical Research 2020; 1:95

doi:10.4081/acbr.2020.95 circumcision is not a common practice. Complications following neonatal circumcision do not commonly include penile amputation. ${ }^{1,2}$ In some areas, adult group circumcision is a common cultural practice of initiation into adulthood and is fraught with complications including penile amputation. ${ }^{3,4}$ Penile amputation is a rare urologic emergency which bedevils the patient with major functional and psychological consequences. ${ }^{5}$ Reconstruction also poses a significant challenge depending on the level of amputation. There is a paucity of published case reports of traumatic penile amputation during circumcisions in our environment. We herein describe a case of adult circumcision that resulted in the amputation of the penis, which was successfully managed using split skin graft with tie over dressing.

\section{Case Report}

A 32 years-old man was referred to us on account of a defect at the distal portion of his penis. He sustained amputation at the distal end of his penis while undergoing circumcision under local anaesthesia in a maternity home under the care of a midwife. The distal part of the penis together with the fore skin was removed. There was profuse uncontrollable bleeding necessitating transfer to a hospital where haemostasis was secured. Healing was prolonged and resulted in narrowing of the urethral opening, dysuria, poor stream which improved on straining; purulent urethral discharge and haematuria. He later developed a hard swelling at the distal urethral opening with occasional passage of stones in urine and erectile dysfunction. Removal of the mass with an attempt at reconstruction in a private hospital was done. The mass was said to have revealed multiple multifaceted stones. He was then referred to us due to the failed attempt at reconstruction.

He sought for the circumcision out of a desire for his penis to be like that of his circumcised male friends. He lost his parents in early childhood and as such did not know why he was not circumcised earlier. He is not a known psychiatric patient. He was sexually active and had four children prior to the incident.

Examination revealed young man with a penile amputation stump, absent corona and glans, an ulcer at the distal end and a urethral catheter in-situ (Figure 1).

He was admitted and wound bed preparation commenced. He subsequently had Split Thickness Skin Grafting (STSG). Intra operative findings included well granulated penile stump, with a stretched length of $8 \mathrm{~cm}$ from the pubis. The granulation tissue was scraped; a sheet of split skin graft harvested, prepared, was laid on the wound and anchored using polyglactin 4/0 to the distal penile skin edge and the urethral mucosal edge. A tie over bolster dressing using tulle gauze and povidone iodine wrung gauze was applied (Figure 2).

Graft take was $98 \%$, and he was discharged after donor site (the right thigh) healing and graft was certified stable (Figure 3).

He was followed up for one year, has maintained good urinary stream and has had successful coitus but still complains of weak erections. 


\section{Discussion}

Penile amputation is a rare injury. Self-mutilation, trauma, and amputation following disputes are the possible causes in adult patients. In pediatrics, the main etiology is circumcision but it is a rare complication. Self-mutilation due to psychiatric disorders is a common etiology in the western societies. ${ }^{5}$ Our patient sustained his injury following adult circumcision, a procedure that is seldom performed in the adult population in this setting.

Circumcision is one of the most common operations in urology, which is usually a safe and simple procedure with low morbidity even when it is performed in adults once it is by a professional. ${ }^{1,6,7}$ However, serious complications including penile amputation and death can occur when circumcision is performed by non professionals, especially in adults. There have been reports of penile mutilation and deaths of Xhosa initiates in Lusikisi, a small village in the Eastern Cape following group circumcision of adolescents and young adults as a form of initiation into adulthood. ${ }^{3,4}$ The penile injury from circumcision is diverse: from infections to disfigurement or partial to total amputation of the penis. ${ }^{8}$ Our patient was a victim of unprofessional practice as it was a midwife who performed the procedure, which resulted in partial amputation, life threatening bleeding and urethral stenosis. Although, there is no uniform guideline for penile reconstruction, the goal is to either create or restore both a functional and aesthetic phallus with the ability to void while standing and to achieve sexual function. ${ }^{9}$ Options depend on the nature and level of amputation. Reimplantation applies to all cases of total amputation, providing that the amputated part is available or not completely destroyed. ${ }^{10}$ In this sub region, unavailability of amputated segment is a common occurrence and when available it may not be viable due to poor preservation. To maintain viability, it is important that the amputated segment should be cleansed using normal saline, wrapped in damp saline dressings, enclosed in a cellophane and kept cool by a separate ice compartment using the "bag-within-a-bag" technique"1 Macroscopic reimplantation which is considered to be a form of composite graft could be done with some level of success but microsurgical technique with neurovascular anastomosis is the gold standard where the expertise and facilities are available. This provides improvement in tissue survival rate, sensation, and erectile function. . $^{8,10,12,13}$

When reimplantation is not feasible, various reconstructive options including pedicled and free flaps have been described. ${ }^{9}$ For partial amputation, measures to augment penile length and or resurfacing are deployed. Resurfacing could involve Split-Skin Graft (SSG) for the glans and full-thickness graft for the shaft to achieve a more natural cosmetic appearance. ${ }^{13}$

However because of the contour it is usually difficult to maintain a split thickness graft in the area which can lead to poor graft take and subsequent contracture and poor cosmesis. ${ }^{14}$ Various measures have been proposed to overcome this challenge including the use of negative pressure wound therapy, quilting of the graft, and recently, Malone et al. ${ }^{15}$ described the tie-over dressing for graft application (the TOGBA technique) as a modality for glans resurfacing following excision of distal penile cancers. Our patient had a partial penile defect involving the distal penis and STSG with tie over dressing was the treatment modality employed in his management with good results.

Although skin grafts give good cosmetic result, there has been concern regarding sensitivity especially in cases of total glansectomy. This may be more pronounced when the corporal tissues were also amputated like our patient had as against peel- ing of the glans with intact corporal tissue as in glans excision for carcinomas. This may also affect preservation of sexual function. Although our patient has had return of some level of sensation

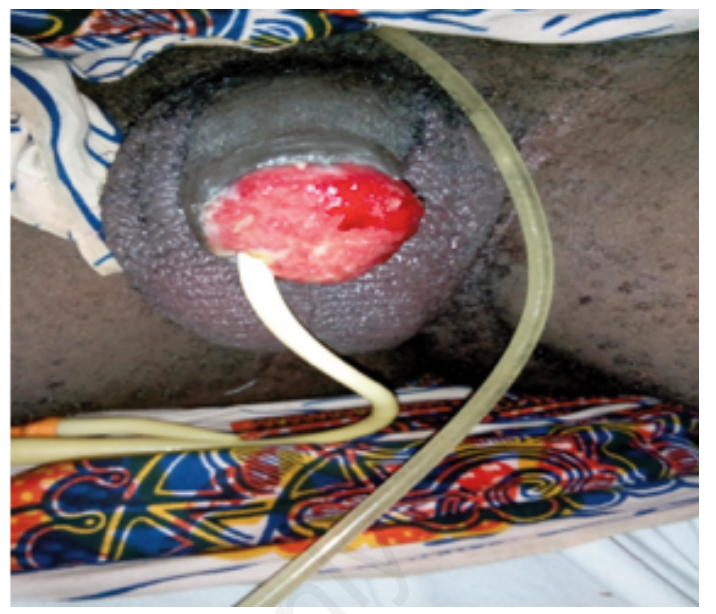

Figure 1. Penile stump at presentation with ulcer at the distal end

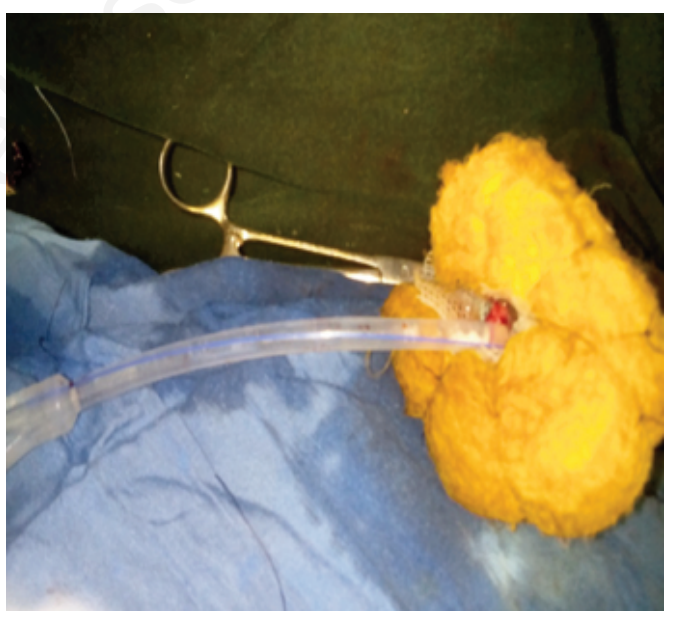

Figure 2. Graft with tie-over dressing applied.

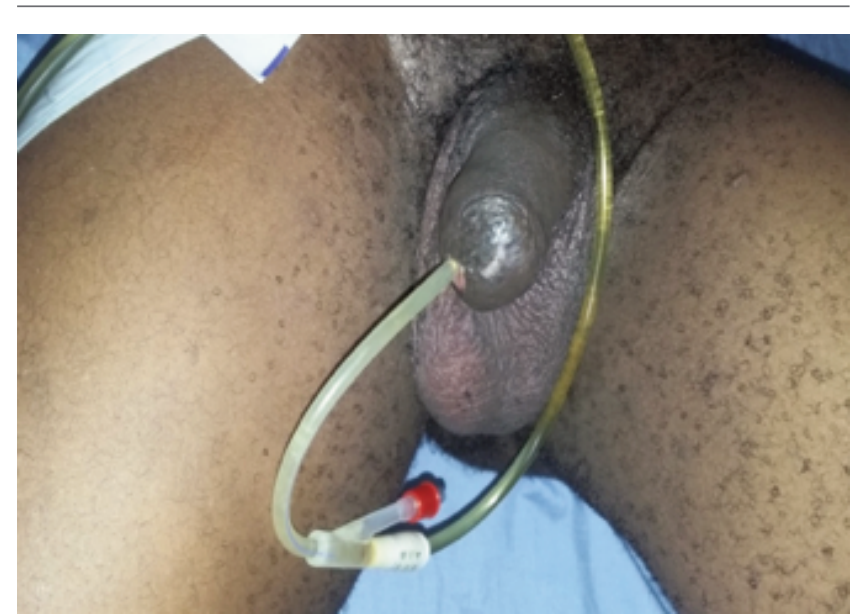

Figure 3. Penis after treatment just before removal of catheter. 
and a successful attempt at coitus, he still has weak erection and long-term sexual function requires to be further evaluated. However, reports on preservation of sexual function following similar penile surgeries have been inconsistent and there are no validated tools for evaluating that. ${ }^{16}$

\section{Conclusions}

Adult circumcision rarely results in penile amputation and should be left for professionals to avoid such mishap. Satisfactory outcome can be achieved by STSG if sufficient length is preserved. However, there is need to develop validated tools for evaluating sexual function.

\section{References}

1. Osuigwe AN, Ikechebelu JI, Okafor PIS. Circumcision related complications in the male; experience amongst the Igbos of southeast Nigeria. Afr J Urol 2004;10:246-51.

2. Okeke LI, Asinobi AA, Ikuerowo OS. Epidermioogy of complications of male circumcision in Ibadan, Nigeria. BMC Urol 2006;6:5-7.

3. Moodley K, Rennie S. Penile transplantation as an appropriate response to botched traditional circumcisions in South Africa: an argument against. J Med Ethics 2018;44:86-90.

4. Sidley P. Botched circumcision lead to arrest for murder. BMJ News 1996;313:647.

5. Raheem OA, Mirheydar HS, Patel ND, et al. Surgical management of traumatic penile amputation: a case. Report and review of world literature. Sex Med 2015;3:49-53.
6. Sowande OA, Adejuyigbe O. Circumcision mishaps: a continuing challenge in the developing countries. East Central Afr J Surg 2019;14:109-13.

7. Holman JR, Army M. Adult circumcision. Am Fam Physician 2018;59:1514-8.

8. Kim JH, Park JY, Song YS. Traumatic penile injury: from circumcision injury to penile amputation. Biomed Res Int 2014 doi:10.1155/2014/375285.

9. Salgado CJ, Eidelson S, Madalon R, Sun Z. Penile Reconstruction. Anaplastol 2012;1: doi:10.4172/2161-1173. $1000 \mathrm{e} 105$

10 Kochakarn W. Traumatic amputation of the penis. Braz J Urol 2000;26:385-9.

11 Eswara JR, Brandes SB. Penile replantation. Abdominal Key. 2020; Available from:. https://abdominalkey.com/penilereplantation. Accessed: 27th July 2020.

12 Pakmanesh H, Sharifian R, Ashabyamin M. Different aspects of penile amputation; surgery, forensics, and psychiatry (case report and short review). Arch Trauma Res 2017;6:101-4.

13 Garaffa G, Gentile V, Antonini G, et al. Penile reconstruction in the male. Arab J Urol 2013;11:267-71. doi:10.1016/j. aju.2013.04.003.

14 Djordjevic ML, Palminteri E, Martins F. Male genital reconstruction for the penile cancer survivor. Curr Opin Urol 2014:427-33. doi:10.1097/MOU.0000000000000068.

15 Malone PR, Thomas JS, Blick C. A tie-over dressing for graft application in distal penectomy and glans resurfacing: the TODGA technique. BJU Int 2011;836-40. doi:10.1111/j.1464410X.2010.09576.x.

16 Kane HFO, Pahuja A, Ho KJ, et al. Outcome of glansectomy and skin grafting in the management of penile cancer. Adv Urol 2011;240824. doi:10.1155/2011/240824. 